\title{
A produção do espaço e sua relação no processo de saúde - doença familiar
}

\section{space production and its relation in the health process - family disease}

\author{
Juliana Maria Damelines Pareja \\ Universidade Federal de Viçosa. Centro de Ciências Humanas, \\ Letras e Artes. Departamento de Economia Doméstica. Viçosa, \\ MG, Brasil. \\ E-mail: juliana.damelinesळgmail.com

\section{Francismara Fernandes Guerra} \\ Universidade Federal de Viçosa. Centro de Ciências Humanas, \\ Letras e Artes. Departamento de Economia Doméstica. Viçosa, \\ MG, Brasil. \\ E-mail: francismarafernandesळyahoo.com.br

\section{Sidnea Ribeiro Vieira. Enfermeira} \\ Universidade Federal de Viçosa. Centro de Ciências Humanas, \\ Letras e Artes. Departamento de Economia Doméstica. Viçosa, \\ MG, Brasil. \\ E-mail: sidnea®ymail.com

\section{Karla Maria Damiano Teixeira} \\ Universidade Federal de Viçosa. Centro de Ciências Humanas, \\ Letras e Artes. Departamento de Economia Doméstica. Viçosa, \\ MG, Brasil. \\ E-mail: kdamianoळufv.br
}

\section{Correspondência}

Avenida Peter Henry Rolfs, s/n, Campus Universitário. Viçosa, MG, Brasil. CEP 36570-000.

\section{Resumo}

Este artigo tem como objetivo propor uma forma de análise social do processo saúde-doença na família, desenvolvendo o conceito de espaço sob a perspectiva da teoria ecossistêmica e conceptual da determinação social em saúde. Primeiramente, uma discussão do conceito de "família" é feita, considerando as vertentes social e ecológica do princípio de ordem e reprodução. Em seguida, discute-se sobre nutrição e trabalho como formas de adaptação, estratégias e administração de recursos das famílias, para que se organizem saudavelmente no ecossistema e como ecossistema, assim como para produzir o espaço. Nesse contexto, procura-se estabelecer que a produção social do espaço e sua organização estruturam as condições de vida de seus ecossistemas, bem como das formas de relacionamentos entre as pessoas e o ambiente, que podem desencadear o processo saúde-doença familiar. Finalmente, procura-se estabelecer como se abordar socialmente o processo saúde-doença na família, segundo sua relação na produção social do espaço. Palavras-chave: Processo Saúde-Doença; Sistema; Ambiente; Produção Social do Espaço; Família. 


\section{Abstract}

This article aims to propose a social analysis of the process of health-illness in the family, developing the concept of space from the perspective of ecosystem theory and concept of social determinants of health. First, it is a discussion on the concept of "family", considering the social and ecological aspects of the order and reproduction principle. Then, a discussion on nutrition and work as forms of adaptation, strategies and administration of families' resources, to organize themselves in an ecosystem and as ecosystem, as to produce space. In this context, we tried to establish that the social production of space and its organization structure the living conditions of their ecosystems and forms of relationships between people and their environment, which can trigger the process health-disease. Keywords: Process of Health-Illness; System; Environment; Social Production of the Space; Family.

\section{Introdução}

Quando a doença aparece na unidade familiar, acarreta-se uma possível desvantagem ecológica e uma diferenciação social nesse sistema. Como resultado dos processos de produção e reprodução social, a doença mostra identificáveis diferenças e distribuições de pessoas e classes. Os processos de produção e reprodução do espaço acontecem em escalas, como na família ou no lar. Por isso, é necessário entender como se dão ou como podem aparecer os processos de saúde e enfermidade nestes grupos humanos. Para tanto, propõe-se uma reflexão conceitual de como se dão os processos de saúde e enfermidade nas unidades familiares sob a perspectiva da determinação social da saúde, tendo como eixo de ação a compreensão do espaço, associada à teoria ecossistêmica.

A teoria ecossistêmica desenvolve o conceito de espaço, necessário ao entendimento de família, como algo físico que envolve troca de informação, matéria e energia. No entanto, a família cria e reproduz o espaço, que não é necessariamente físico, mas também social, que é mais amplo do que o conceito empregado pela ecologia. Dessa forma, o espaço define-se, por exemplo, nas práticas sociais e no corpo, e implica, ainda, em normas de produção e de reprodução de informação, matéria e energia no tempo.

O espaço e a forma de sua produção geram condições de exposição e vulnerabilidade nos diferentes ambientes e sistemas, desenvolvendo uma dialética entre indivíduos, espaço, e saúde-doença. A família e o espaço estabelecem relações para seu desenvolvimento e sua adaptação através da interação com os sistemas materiais e simbólicos, conforme as práticas, habitus e estilos de vida, que estruturam suas condições de vida. Igualmente, os indivíduos e as famílias estão em interdependência e inter-relação com sistemas de ordem geral e proximal que podem delimitar ou impulsionar as formas de agir. Dessa forma, uma unidade familiar saudável tem mais oportunidades de adaptar-se na sociedade, tal como uma sociedade marcada pela exclusão pode afetar essa salubridade. 


\section{Marco teórico}

Para construir um objeto que permita uma avaliação contextualizada e biopsicossocial do processo, é necessário gerar conhecimento sobre o caráter social dos processos saúde-doença que permita ir além do objeto direto da medicina clínica e da epidemiologia (que leva em conta, apenas, aspectos biológicos da enfermidade). As investigações sobre os padrões de desgaste da saúde e do perfil patológico devem incluir os agravos à saúde e os membros dos grupos humanos envolvidos no processo de saúde-doença (por exemplo, comunidades, cidades, bairros ou famílias) e suas características comuns. A coletividade social e sua história determinam características e probabilidades na variação biológica individual que geram as doenças; assim a relação entre o processo de saúde-doença se dá de forma coletiva e individual (Laurell, 1981).

Para tanto, apresentamos uma discussão que se inicia na conceituação de família, perpassa a organização do sistema familiar sob a ótica da Teoria Ecossistêmica, e o processo saúde-doença, sob a ótica da Teoria da Determinação Social da Saúde, para, então, propormos uma abordagem do caráter social das doenças que se desenvolvem no núcleo familiar.

\section{O que é família?}

A família é um conceito crucial de análise, tanto para as ciências sociais quanto ecológicas, porque define a estrutura inicial e básica da inter-relação entre os indivíduos com seu espaço e o ambiente social. 0 conceito de família nas ciências sociais diz respeito a um sistema social organizado, enquanto na ecologia trata-se de um ecossistema humano. Mas, ambas as áreas concordam em afirmar que família é um princípio de ordem, de um conjunto de indivíduos inter-relacionados.

As ciências sociais têm discutido o conceito de que "família" são tipos e estruturas de relações de parentesco de um conjunto de indivíduos ou sujeitos presentes e conviventes num determinado lugar, o qual é construído simbolicamente e apropriado pela linguagem (Lévi-Strauss, 1966). A palavra "família" envolve uma ordem e uma organização social, reproduzidas no espaço-tempo, que podem agrupar um conjunto de indivíduos aparentemente ligados entre si pela aliança, afiliação ou adoção, onde a coabitação pode ser uma de suas características (Bourdieu, 1993). Um conceito próximo e complementar refere-se às famílias como grupos constituídos por pessoas que estabelecem entre si relações de aliança, descendência e consanguinidade, mas não são necessariamente as unidades básicas de parentesco (Durham, 1983).

Além disso, a família é um sistema real e material, pois se constrói e se reconhece socialmente, agrupando um conjunto tangível de pessoas ou indivíduos. Ademais, é um sistema simbólico, porque é uma ideologia presente nas sociedades e nos grupos humanos, pelo qual se conhece e se constrói a realidade. As suas representações constituem um ponto de vista pessoal ou coletivo, segundo a posição social dos agentes ocupantes do espaço social (Bourdieu, 1993).

O conceito ou a palavra "família", segundo a biologia, envolve uma unidade sistemática que designa uma ordem e um gênero (Campbell; Reece, 2007). Em particular, para a ecologia aplicada aos animais humanos, é uma ordem orgânica de relações que agrupa um conjunto organizado e interdependente de indivíduos em constante interação através de comportamentos e papéis, regulados por regras e funções dinâmicas que existem no interior (ambiente próximo) e exterior (ambiente distal) desse conjunto, e que definem a identidade e o ambiente familiar e próximo (Bronfenbrenner, 1988; Damiano, 2005; Minuchin et al., 2009).

Entendendo, assim, a família como um princípio ecológico, esta concorda com um sistema agregado de indivíduos e objetos justapostos em regular interação ou interdependência: uma totalidade ordenada e ativa (Breilh, 1991).

A família estabelece normas e valores, constituindo-se como um grupo localizado em um espaço-tempo compartilhado, onde cada um tem rol e papel definidos (sexualidade, reprodução, socialização e cuidado) em função do desenvolvimento da vida social. Assim, conforme as posições dos sujeitos no mundo familiar (mãe, pai, avó, irmã, irmão etc.), social (trabalhador, rico, pobre) e segundo o poder 
possuído por cada membro da família, vão ser os modos de interação entre os mesmos (Bourdieu, 1993).

A família é um elemento da estrutura da sociedade, responsável pela reprodução biológica e social do ser humano e a manutenção da espécie humana, que sintetiza a produção da saúde numa escala microssocial. Nela satisfazem-se as necessidades que estão na base da conservação, fomento e recuperação da saúde (Louro, 2003).

As famílias podem ser grupos sociais que produzem e reproduzem o espaço, por meio de relações e formas de coexistência com a natureza, capazes de mudar o entorno através do tempo ou da história (Mahecha, 2003; Santos, 1996). Assim, o espaço é a natureza modificada pela força ou ação humana e, portanto, caracteriza-se como uma construção social (Rojas, 1998). Essa força ou esta ação, que modifica a natureza, denomina-se "trabalho humano".

A produção social do espaço é também criação em termos de adaptação, já que a humanidade é uma espécie terrestre dotada de capacidades e potências transformadoras, que as utiliza para modificar o meio quando procura o sustento e efetua a reprodução, e, como outras espécies, adapta-se aos meios que ajuda a construir (Harvey, 2009).

Igualmente, a família estrutura uma forma particular de interação entre indivíduos e ambiente ou natureza, que opera ao longo do tempo, a qual aporta os primeiros mecanismos que produzem o desenvolvimento humano (Bronfenbrenner, 1988; Martins et al., 2004). O desenvolvimento humano é a evolução das pessoas, que sucede durante processos progressivamente mais complexos de interações recíprocas entre um organismo humano, pessoas, objetos e símbolos no ambiente imediato e no tempo, denominado processos proximais (Bronfenbrenner, 1988; Martins et al., 2004; Tudge, 2008). Em tais interações, efetuam-se processos de produção e reprodução do espaço e de troca de matéria, informação e energia (Damiano, 2005). A troca, por sua vez, é um padrão da relação entre produção e consumo e da adaptação humana ao ambiente e ao espaço social, que envolve princípios da ciência econômica (Ingold, 2001).

Na teoria ecossistêmica de Bronfenbrenner (1988), a família é um sistema humano que interatua com o ambiente ou contexto, envolvido em sistemas inter-relacionados (Tudge, 2008). São quatro os sistemas de interações definidos num mapa ecológico: sistema de inter-relações imediato ou microssistema, no qual a pessoa em desenvolvimento passa boa parte do tempo engajada em atividades e interações; sistema de inter-relações distantes ou macrossistema, o equivalente à cultura; sistema de inter-relações entre os vários microssistemas ou mesossistemas (tais como: casa, escola, grupos de pares etc.), no qual os indivíduos passam uma quantidade de tempo significativa; e o exossistema, que é sistema de inter-relações com contextos nos quais os indivíduos não estão situados de fato, mas que exercem importante influência indireta sobre o desenvolvimento desses indivíduos (Bronfenbrenner, 1988; Martins et al., 2004; Tudge, 2008).

\section{Nutrição e trabalho: formas de adaptação, estra- tégias, e administração de recursos das famílias}

Smith (1972) introduziu o conceito de ecossistema como fundamento para ampliar a ecologia humana, assinalando que a ecologia significa o estudo da economia da natureza e redefinindo sistema como um agregado ou uma união de objetos justapostos em regular interação ou interdependência. Segundo a ecologia aplicada, as pessoas e seus ambientes não devem ser vistos somente em termos econômicos, que entendem a família ou o lar como unidade econômica ou como agente, esquecendo-se da influência das dinâmicas familiares na resolução e na busca de recursos para a sobrevivência (Canning et al., 1994).

Por isso, é importante diferenciar a definição de ecologia da definição de ecologia humana. A ecologia estuda a relação entre os seres vivos e seu ambiente, sua distribuição e abundância, bem como a interação entre os organismos e seu ambiente. 0 ambiente inclui as propriedades físicas que podem ser descritas como a soma de fatores abióticos locais e os demais organismos que compartilham esse habitat (Begon; Towsend; Harper, 2006). Já o ecossistema estrutura-se a partir de um sistema formado por uma comunidade natural de seres vivos em interação com componentes bióticos (conjunto de seres vivos: flora e fauna) e abióticos (seu am- 
biente físico) (Campbell; Reece, 2007). Em particular, sistemas que incluem seres humanos também devem considerar a constituição de relações sociais (Damiano, 2005).

Apesar de a ecologia humana se basear em conceitos oriundos da ecologia, não é propriamente uma das ramificações da ecologia. Para muitos, estudar a "relação do homem com o ambiente" inclui fatores econômicos, sociais e psicológicos. Para outros, a ecologia humana tem objetivos e metodologias mais específicos, que incluem entender o comportamento humano sob variáveis ambientais (Begossi, 1993).

Para entender a família na teoria ecossistêmica, pode-se começar observando como são organizados os comportamentos e as relações da família em termos econômicos e ecológicos. Segundo Ingold (2001), em condições racionais de adaptação, a decisão dos grupos humanos na procura de alimentos toma como base a teoria do "forrageamento ótimo". Essa teoria considera o comportamento do forrageiro (indivíduo ou grupos de indivíduos), como um balanço entre os benefícios da nutrição e dos custos para obter os alimentos, assim como o gasto de energia ou o risco de morrer no processo de procura alimentar. De acordo com a seleção natural, o forrageiro tem que diminuir os custos e aumentar ao máximo os benefícios (Campbell; Reece, 2007).

A incorporação dessa teoria aos grupos humanos ou à ecologia humana remete ao forrageiro como homem econômico, que precisa aplicar regras de decisão para maximizar os benefícios dos recursos obtidos e os custos energéticos investidos na aquisição de dito recurso, com a finalidade de se desenvolver em contextos ambientais ou espaços sociais específicos (por exemplo: família, lugar ou território) (Ingold, 2001; Cuenca, 2006). Complementarmente, o ambiente, segundo a teoria do forrageamento, condiciona a adaptação e a seleção natural ao prover recursos úteis para a sobrevivência humana e impõe limites ao conferir riscos e perigos (Cuenca, 2006).

Nesse contexto, também, podemos entender dois aspectos complementários das regras de decisão e dos recursos investidos. O primeiro aspecto considera a alimentação como a base de um bom desenvolvimento corporal e orgânico, fundamento da imunidade e da saúde, fonte de energia, que gera uma resistência orgânica à infecção para os indivíduos e grupos de indivíduos. Esse aspecto também incorpora os conflitos relacionados com a nutrição e a alimentação, influenciados por tradições, valores culturais, normas sociais, políticas estatais e do comércio (Barona, 2012), ao dizer que o desenvolvimento corporal encontra-se estritamente relacionado com o estabelecimento social e as relações que ali são desenvolvidas.

O segundo aspecto considera a busca dos meios para satisfazer as demandas e necessidades de alimentos, condicionada ao desenvolvimento do trabalho. 0 trabalho é uma atividade orientada para um fim que envolve um objeto, meios e um processo, mediante os quais as pessoas se transformam e transformam a natureza para a satisfação de suas necessidades (Marx, 1980). Mediante o trabalho, as pessoas produzem o espaço e transformam a natureza criando ambientes sociais, em procura da satisfação de necessidades vitais.

Nutrição e trabalho são formas de adaptação ao espaço porque implicam relacionamentos com pessoas e ambientes que podem virar modos de vida e habitus. Adaptação é um conceito que tenta explicar como organismos, indivíduos ou pessoas respondem às mudanças ambientais mediante ajustes morfológicos e funcionais, como a regulação, aclimatação, acoplamento ou feedback, direcionadas a manter uma relação estável entre pessoa e entorno. A adaptação é um processo no qual tempo e ambiente são necessários para que os grupos humanos se ajustem com as mudanças ambientais. O grau de adaptação de uma população é medido segundo seu nível nutricional, sua condição de saúde-doença e a efetividade dos mecanismos que controlam o crescimento demográfico nos períodos de flutuações ambientais (Cuenca, 2006).

Por outro lado, as estratégias adaptativas na produção do espaço social desenvolvem formas de administração de recursos nos grupos humanos, nas quais os recursos são os meios para satisfazer as demandas crescentes do indivíduo (necessidades e desejos). Assim, o principal objetivo da administração de recursos na família é o uso efetivo dos recursos familiares (os quais são escassos) para satisfazer necessidades e criar um meio ambien- 
te propício para o desenvolvimento do potencial humano (Damiano, 2005). Nos grupos familiares, a administração dos recursos tem uma estreita relação com os modos de vida, pois são as formas de agir internamente na família para desenvolver-se na sociedade ou ambiente social (Bourdieu, 1993).

A situação de saúde de um espaço populacional particular, como a família, em um momento específico, está influenciada pela economia, pelo ambiente natural (clima, solos, relevo e outras), pela experiência biológica da população em contato com diversos agentes patogênicos, segundo os estilos e as condições de vida, assim como pela estrutura política da atenção em saúde. A conjugação dessas diferentes influências vai gerar o processo saúde-doença (Rojas, 1998).

\section{A determinação social em saúde: como a produção social do espaço cria ambientes que incidem no processo saúde-doença}

A Determinação Social em Saúde afirma que, o processo saúde-enfermidade é resultante da produção social do espaço. O indivíduo, ou grupo de indivíduos, transforma, interatua e desenvolve ambientes naturais, biológicos, culturais, políticos e econômicos, que serão determinantes no processo saúde-enfermidade. Igualmente, o processo saúde-enfermidade ocorre em uma área e em um momento determinados, onde as interações e a produção do ambiente sofrem a influência de fatores diversos (Laurell, 1983; Breilh, 2010; Rojas, 1998; Aquino et al., 2012).

Para entender o processo saúde-enfermidade no mundo moderno, segundo uma abordagem ecológica, é preciso entender o conceito de espaço relacionado com o tempo (história) e o contexto (sistemas) (Bronfenbrenner, 1988). E não apenas como o local físico onde ações, eventos e processos acontecem e no qual matéria e energia existem (Damiano, 2005). Deve-se tentar entender o espaço como uma categoria de análise, como um conjunto inseparável de sistemas de objetos e ações que alberga uma produção histórica da realidade (política, econômica e cultural), intermediando nos determinantes estruturais da sociedade e da situação de saúde da população (Aquino et al., 2012). O espaço é uma totalidade cujos componentes são as pessoas, as instituições, o meio ecológico, as infraestruturas etc. (Santos, 1996).

\section{As diferenças espaciais e ecológicas são proporcionais às diferenças na mortalidade e morbidade}

Na produção social do espaço, formam-se organizações e grupos sociais de maneira desigual, de acordo com a natureza dos processos socioeconômicos e político-econômicos, que definem diferenças espaciais e ecológicas (Harvey, 2009). As diferenças espaciais no mundo moderno são determinadas por: práticas sociais de acumulação de capital em um contexto de trabalho e mercados competitivos; técnicas de transformação da natureza; e vigilância ou controle da informação e supervisão social (Giddens, 1990). Paralelamente, as diferenças ecológicas que são definidas em dita produção decorrem das interações entre indivíduos ou organismos e os ambientes natural, físico-biológico, sociocultural e construído (ecossistema humano) (Damiano, 2005).

Aplicando este conhecimento ao processo saúde-doença, podemos dizer que na realidade social existem diferenças no espaço que vão gerar vantagens e desvantagens para o desenvolvimento do ser humano e para sua atuação. Estas vantagens e desvantagens explicam as variações na morbidade e mortalidade, podendo ser entendidas como recursos sociais e materiais. Como exemplo, podemos citar o acesso e a utilização diferenciados de recursos relacionados à nutrição, aos serviços de saúde, à informação, às oportunidades de trabalho, à renda, às oportunidades de educação, à moradia, à qualidade ambiental, ao cuidado parental, entre outros (Laurell, 1981; Bronfenbrenner, 1988; Breilh, 1991).

Por exemplo, existe uma probabilidade diferencial de morrer na temporã infância (segundo a classe social), porque o risco de morrer durante os dois primeiros anos está diretamente relacionado à ocupação do pai, ou seja, ao modo como este se insere na produção. Assim, a probabilidade de que um filho do proletariado morra antes dos dois anos 
de idade é quatro vezes maior que um filho da alta ou média burguesia; o risco do menino de área rural, cinco vezes maior (Laurell, 1981).

$\mathrm{O}$ acesso diferenciado encontra-se determinado pela forma como as estruturas política, cultural e econômica são definidas nos territórios. No momento atual, o peso da acumulação acelerada de capital e de uma cultura voltada ao modelo civilizador dominante têm moldado espaços institucionais, políticos e técnicos (Breilh, 2010), que podem criar ambientes que interferem na saúde das pessoas.

$\mathrm{O}$ ambiente se refere à área de acontecimentos e condições que influem sobre o comportamento de um sistema (Arnold, 1998). Consiste na totalidade dos arredores do ser humano, fornecendo o contexto para seu comportamento e desenvolvimento, e relacionando-se, direta ou indiretamente, com o sistema. Os sistemas humanos estão inseridos em seu ambiente, inter-relacionando-se intensamente com ele (Damiano, 2005). Assim, além de ser entendido como uma área circundante ao ser humano, o ambiente também representa a resposta e o resultado da produção e reprodução do espaço. É a natureza humanizada, chamada por muitos de ambiente humano.

\section{Como se estrutura o ambiente humano onde acon- tece o processo saúde-doença?}

O ambiente humano é estruturado de maneira diferenciada por atores reconhecidos (agentes) que operam dentro de um contexto social específico chamado estrutura. As relações entre estrutura e agentes são mediadas por uma série de instituições que permitem construir a ação; igualmente, o ambiente humano encontra-se baseado na interdependência entre a intencionalidade da conduta individual, os sistemas e as estruturas sociais (Knox, 1994). A forma como se estrutura o ambiente humano em interdependência com agentes e instituições irá determinar a forma como acontece o processo saúde-doença. Assim, podemos propor três categorias de análise aplicáveis ao entendimento desta relação.

Por exemplo, o comportamento de destinação adequada dos dejetos humanos depende da conduta individual de um agente (indivíduo ou grupo familiar), que reconhece esta prática ou ação como determinante à manutenção de sua saúde e qualidade de vida. Porém, para a concretização deste comportamento, é necessária a existência de uma rede de captação destes mesmos dejetos que, para que esteja disponível, depende da iniciativa da estrutura pública institucional. Igualmente, a ausência de uma adequada destinação de dejetos, favorece ambientes focais propícios ao desenvolvimento de doenças e indica uma incapacidade do Estado no controle das condições de vida dos cidadãos.

\section{Figura I - Categorias de análise na estruturação do espaço aplicáveis à análise social do processo saúde- -doença}

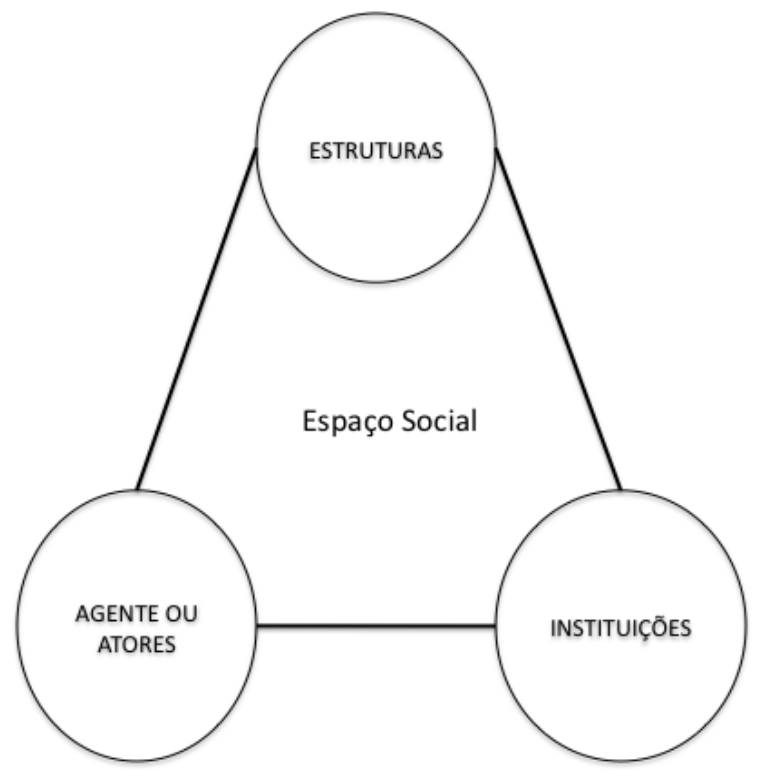

Os fluxos de interdependência entre intencionalidades individuais, sistemas e estruturas sociais do ambiente humano determinam, de forma diferenciada, a estruturação da vida social (Knox, 1994) e das condições de vida no espaço (Laurell, 1981), que podem desencadear o processo saúde-doença.

Como aproximar a estruturação do ambiente humano da análise da determinação social?

A estruturação diferenciada do ambiente humano define as condições de vida da sociedade e seus 
grupos, que reproduzem as ideologias e modos de agir. As estruturas no processo saúde-doença são de dois tipos: geral e proximal. A estrutura de escala geral, na qual transcorre a vida das pessoas, é representada pelas leis e regras econômicas, culturais e políticas. Tais regras, principalmente no mundo moderno, são influenciadas pela lógica de acumulação de capital e geram as condições macrossociais do ambiente humano (Breilh, 1991).

Outro tipo de estruturas são aquelas que vão garantir tipos de ordem e organização numa escala menor como a proximal, onde as pessoas desenvolvem sua vida, como a família, a comunidade, o trabalho, entre outros. E onde são transmitidas e incorporadas as tradições, as crenças, o valor, ou seja, onde é incorporado parte do sistema ideológico, e onde se estabelecem os modos de viver e as formas de adaptação no mundo social.

Individualmente, a modificação do contexto pode ocorrer de três maneiras: de forma passiva, quando o indivíduo influencia o comportamento de outros apenas com a sua presença no ambiente; de forma ativa, quando o indivíduo utiliza suas capacidades físicas, mentais e emocionais para mudar o ambiente; e, de forma mais ativa ainda, quando utiliza seu esforço e vontade para conseguir alterar o contexto em que está inserido. As formas de conjugação entre estruturas, agentes e instituições vão condicionar os aspectos sociais da exposição e da vulnerabilidade das pessoas a processos de adoecimento.

Um exemplo dessas escalas - geral, proximal e individual - é o caso da dengue, uma enfermidade transmitida pelo mosquito Aedes aegypti. 0 desenvolvimento do vetor ocorre em águas paradas, acumuladas nos resíduos provenientes do uso e consumo dos cidadãos e que são deixados em locais impróprios do ambiente (domínio proximal), gerando nichos favoráveis ao seu crescimento. Esse desenvolvimento também pode ocorrer dentro dos domicílios (domínios proximal e individual) construídos pelos indivíduos e pelas instituições públicas ou privadas, em lugares como vasos de plantas, calhas de recolhimento de água da chuva e vasos sanitários em desuso.

Uma vez infectado, o indivíduo irá necessitar de cuidados que, dependendo da estrutura do sistema de saúde ao qual tem acesso, estarão ou não disponíveis de forma adequada. 0 tipo de cuidado também irá depender das decisões pessoais do indivíduo, da influência do seu grupo familiar e do seu sistema de crenças (domínio geral). Por exemplo, o indivíduo doente pode preferir o cuidado através de práticas alternativas em vez da medicina tradicional. É ele quem está decidindo seu agir no cuidado, mas essa decisão vai depender do aparelho do Estado (domínio geral), atuando como divulgador de informações sobre a prevenção, o tratamento da enfermidade e suas complicações. Além disso, o grupo familiar deverá buscar novas estratégias de funcionamento e organização que garantam a obtenção de recursos e a manutenção de sua funcionalidade dentro deste novo cenário de saúde.

\section{Como se estrutura o processo saúde-doença na família?}

A família desenvolve práticas sociais ou estilos de vida, que resultam da interação entre um habitus e situações da vida cotidiana e que, com o decorrer do tempo, vão reproduzir e produzir o espaço social próximo, em uma escala microssocial (lar, vizinhança, comunidade etc.) (Silva, 2010). Assim, estilos de vida, habitus e situações da vida cotidiana das famílias também irão influenciar o processo saúde-doença no microssistema.

Os condicionantes sociais do processo saúde-doença são os habitus ou esquemas de percepção, estruturados e interiorizados pela sociedade na produção histórica dos grupos humanos. Tais habitus são modificados pela trajetória individual, familiar, social e profissional, de acordo com os sistemas com os quais os indivíduos interagem. O habitus corresponde também a disposições estruturantes, ou seja, intenções que orientam as escolhas práticas e que estruturam a realidade social (González, 2004).

Os habitus são práticas que estão definidas, em parte, dentro dos microssistemas familiares, onde se desenvolvem papéis, atividades e relações cara a cara com os membros que os compõem, os quais possuem elementos que influem no desenvolvimento psicológico e também de saúde das pessoas, agentes ou indivíduos. 
O estilo de vida está representado no conjunto de propriedades que cercam os indivíduos ou grupos: casa, móveis, quadros, livros, bebidas, perfumes, roupas, entre outros. Igualmente, os estilos de vida estão representados nas práticas em que se manifestam suas distinções, por exemplo, as distrações culturais e sociais como o gosto, propensão e aptidão à propriedade material e/ou simbólica de uma categoria de objetos ou práticas classificadas e classificadoras (Bourdieu, 1976)

O estilo de vida é o modo de vida individual, é a forma de viver das pessoas. Relaciona-se com a esfera comportamental e motivacional do ser humano, que alude à forma particular de realização das pessoas como seres sociais, em condições concretas e específicas. Da mesma forma, a família, como grupo particular com condições de vida similares, possui um estilo de vida próprio, que determina a saúde do grupo familiar e seus membros, conhecido como estilo de vida familiar. Dentro do estudo social do processo saúde-enfermidade, é preciso entender o modo e estilo de vida da população, porque eles dependem diretamente do sistema socioeconômico. Assim, as variações ou mudanças desse sistema, podem mudar também o modo, o estilo e a qualidade de vida da população. Da mesma maneira, as mudanças do modo e estilos de vida determinam também mudanças nas condições e na qualidade de vida das pessoas (González, 2004).

O processo saúde-enfermidade acontece em corpos biológicos, como a família ou os indivíduos, que têm uma autonomia relativa de regular seu ambiente interno. Mas essa autonomia depende do grupo no qual se desenvolvem os potenciais genéticos, sociais e de posição no espaço social.

\section{Figura 2 - Aspectos presentes na estruturação das condições de vida nas famílias}

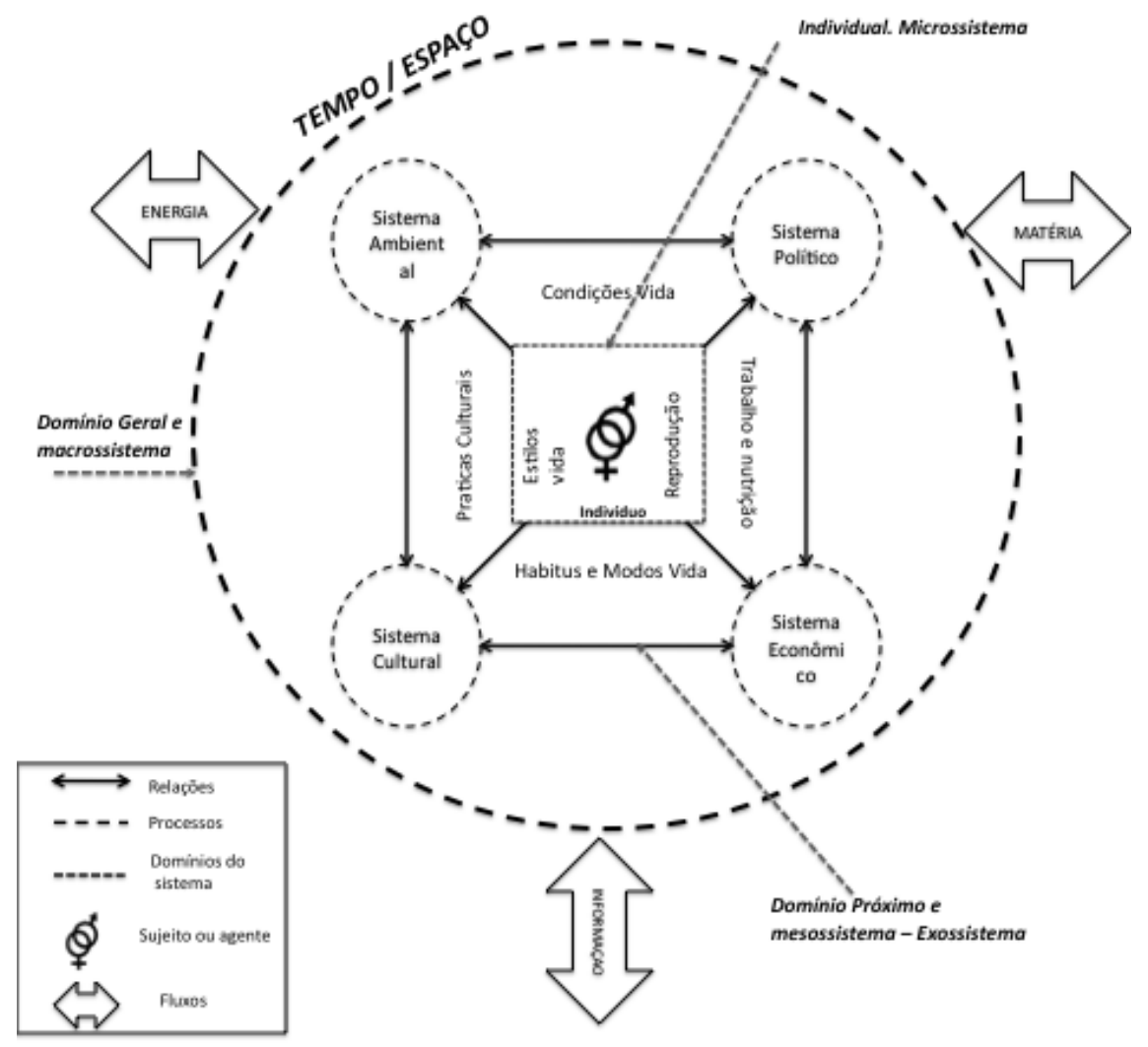


Neste caso, o potencial genético é uma expressão fenomênica que depende das interações sociais para o desenvolvimento de habilidades cognitivas, utilizando recursos sociais, como oportunidades educacionais e laborais (Bronfenbrenner 1988; Silva, 2010;). O potencial social é influenciado por um habitus, que orienta as tomadas de posição referentes ao estilo de vida, ou seja, as escolhas alimentares, o tipo de lazer, a incorporação ou prática da atividade física como rotina. Desta forma, o potencial social tem relação com a produção e desfecho de várias enfermidades.

Finalmente, a posição ocupada pelas famílias no espaço social está relacionada à valorização dos bens materiais e simbólicos (como, por exemplo, o trabalho), que definem as condições gerais de existência, permitindo o acesso à boa alimentação, à moradia e a serviços de saúde. Ou seja, o estado de saúde das famílias está influenciado pelo conjunto de recursos materiais e simbólicos, dos quais elas se apropriam nos diferentes sistemas e estruturas sociais, e que potencializam sua bagagem genética (Silva, 2010).

\section{Considerações finais}

O espaço é constituído de sistemas materiais e simbólicos, nos quais se estabelecem relações de domínio indivisíveis entre pessoas e natureza que configuram e conjugam os grupos sociais e suas formas de agir. Esses grupos sociais, conforme seja sua localização e inter-relação com os diferentes sistemas, vão estruturar ordens e ambientes diversos, de forma hierárquicos.

Um exemplo de ordem e de ambiente é a família, porque ali se formam e reproduzem práticas materiais e simbólicas (como o trabalho, a cultura, os estilos de vida, o habitus) para a adaptação, o desenvolvimento, e a sobrevivência dos grupos sociais. Essas práticas familiares estão inseridas e comunicadas com outros ambientes estruturantes do espaço e seus sistemas no tempo. A conjugação das particularidades dos sistemas do espaço (estruturas, agentes e instituições) demarcam ambientes de exposição e vulnerabilidade das famílias, porque naqueles sistemas acontecem de maneira desigual fluxos de troca de matéria, energia e informação que podem carregar ou estar presentes no processo saúde-doença.

Para entender o processo saúde-doença das famílias, é preciso perceber como é dada a organização e o funcionamento dos microssistemas particulares com os quais as famílias interagem para se adaptar e se desenvolver nos diferentes sistemas do espaço social (sistemas macro, exo e meso), assim como definir quais são os hábitos estabelecidos nas relações de trabalho e administração de recursos, nos estilos de vida familiar e nutrição, nas crenças e ideologias, entre outros, que podem estar presentes nos processos de saúde-doença.

Outro aspecto fundamental para entender dentro do processo saúde-doença são os tipos de trabalho que efetuam as famílias, que são influenciados pelo domínio geral, e representam as formas adaptativas que as famílias desenvolvem para tentar alcançar alimentação e suprir necessidades tanto corporais como culturais. Ao desenvolvimento do trabalho são aplicadas técnicas e tecnologias que modificam a natureza e incidem nas condições de saúde ou doença das famílias e seus integrantes. Igualmente, uma relação fundamental para entender o processo saúde-doença nas famílias, é a divisão do trabalho, das tarefas e dos papéis na unidade familiar, que vão promover o tipo de desenvolvimento e satisfação das necessidades do grupo. Em um microssistema familiar, tal divisão destina-se a construir o espaço social, transformando a natureza e sua própria natureza, em procura do sustento e manutenção de seu estilo de vida, conforme sua interação e sua localização nos diferentes sistemas do espaço. Finalmente, é importante ter em conta que, quando em uma família acontece a enfermidade, a adaptação e a divisão do trabalho, das tarefas e dos papéis podem modificar-se para garantir a superação da enfermidade e continuar garantindo a sustentabilidade da família.

\section{Referências}

AQUINO, R. et al. Estudos ecológicos (desenhos de dados agregados). In: BARRETO, M. L.;

ALMEIDA FILHO, N. B. Epidemiologia \& saúde: fundamentos, métodos, aplicações. Rio de Janeiro: Guanabara Koogan, 2012. p. 175-185. 
ARNOLD, M.; OSORIO, F. Introducción a los conceptos básicos de la teoría general de sistemas. Cinta Moebio: Revista de Epistemología de Ciencias Sociales, Santiago de Chile, v. o, n. 3, p. 40-49, abr. 1998.

BARONA, J. L. La construcción del problema de la nutrición en el periodo entre guerras. In: GARCÍA, M. Alimentación, salud y cultura: encuentros interdisciplinares. Catalunya: Publicacions Universitat Rovira I Virgili, 2012. p. 495-515.

BEGON, M.; TOWSEND, C.; HARPER, J. Ecology: from individuals to ecosystems. Victoria: Blackwell Publishing, 2006.

BEGOSSI, A. Ecologia humana: um enfoque das relações homem-ambiente. Interciencia, Caracas, v. 18, n. 3, p. 121-132, 1993.

BERNAL, I. L. La familia en la determinación de la salud. Revista Cubana Salud Pública, Havana, v. 29, n. 1, p. 48-51, 2003.

BOURDIEU, P. et al. À propos de la famille comme catégorie réalisée. Actes de la recherche en sciences sociales, Paris, v. 100, n. 1, p. 32-36, dez. 1993. Disponível em: <http://www.persee.fr/doc/ arss_0335-5322_1993_num_100_1_3070>. Acesso em: 12 fev. 2015 .

BOURDIEU, P. Gostos de classe e estilos de vida. Actes de la recherche en sciences sociales, Paris, n. 5, p. 18-43, Out.1976. Disponível em: <http:// www.unifra.br/professores/arquivos/8547/89602/ gostos\%2ode\%2oclasse\%20e\%2oestilos\%2ode\%20 vida\%2o(pierre\%2obourdieu).pdf >. Acesso em: 7 mar. 2015 .

BOURDIEU, P. Poder, derecho y clases sociales. Bilbao: Desclée de Brouwen, 2001.

BREILH, J. Epidemiologia: economia, política e saúde. São Paulo: UNESP, 1991.

BREILH, J. Las tres "s" de la determinación de la vida 10 tesis hacia una visión crítica de la determinación social de la vida y la salud. In: PASSOS, N. R.

Determinação social da saúde e reforma sanitária. Rio de Janeiro: CEBES, 2010. p 87-125.

BRONFENBRENNER, U. Interacting systems in human development. Research paradigms: present and future. In: BOLGER, N. et al. Persons in context: developmental process. New York: Cambridge University Press, 1988. p. 25-49.

CAMPBELL, N. A.; REECE, J. B. Biología. Madrid: Editorial médica panamericana, 2007.

CANNING, D. et al. The family and economic development. Cambridge: Harvard Institute for International Development, 1994. Disponível em: <http://citeseerx.ist.psu.edu/viewdoc/download ?doi=10.1.1.194.8310\&rep=rep1\&type=pdf $>$. Acesso em: 26 set. 2015 .

CUENCA, J V. R. Las enfermedades en las condiciones de vida prehispánica de Colombia. Bogotá: Siglo del Hombre Editores, 2006.

DAMIANO, K. A administração de recursos na família: quem? como? por quê? para quê? Viçosa: UFV, 2005.

DURHAM, E. Família e reprodução humana. In: FRANCHETTO, B. Perspectivas antropológicas da mulher. Rio de Janeiro: Zahar, 1993. p. 13-44.

GIDENS, A. As consequências da modernidade. São Paulo: UNESP, 1990.

GONZÁLEZ, L. E. Cambios del modo y estilo de vida; su influencia en el proceso saludenfermedad. Revista Cubana de Estomatología, Havana, v. 41, n. 3, 2004. Disponível em: <http://scielo.sld.cu/scielo.php? script=sci arttext\&pid=So034-75072004000300009\&lng=es \&nrm=iso>. Acesso em: 23 jul. 2015.

HARVEY, D. Espaços de esperança. São Paulo: Edições Loyola, 2009.

INGOLD, T. El forrajero óptimo y el hombre económico. In: DESCOLA, F.; PÁLSSON, G. Naturaleza y sociedad. México, DF: Siglo XXI, 2001. p. 37-59.

KNOX, P. L. Urbanization: an introduction to urban geography. Upper Saddle River: Prentice-Hall, 1994.

LAURELL, A. C. La salud enfermedad como proceso social. Revista Latinoamericana de Salud, México, DF, v. 2, n. 1, p. 7-25, 1981.

LÉVI-STRAUSS, C. A família. In: SHAPIRO, H. L. Homem, cultura e sociedade. Rio de Janeiro: Fundo de Cultura, 1966. p. 308-333. 
MAHECHA, O. D. Debates sobre el espacio en la geografía contemporánea. Bogotá: Universidad Nacional, 2003.

MARTINS, E.; SZYMANSKI, H. A abordagem ecológica de Urie Bronfenbrenner em estudos com famílias. Estudos e Pesquisas em Psicologia, Rio de Janeiro, v. 4, n. 1, p. 63-77, 2004.

MARX, K. El capital. México, DF: Siglo XXI, 1980. MINUCHIN, S.; FISHMAN, H. C. Family therapy techniques. Cambridge: Harvard University Press, 2009.

ROJAS, L. I. Geografía y salud: temas y perspectivas en América Latina. Cadernos de Saúde Pública, Rio de Janeiro, v. 14, n. 4, p. 701-711, 1998.
SANTOS, M. La naturaleza del espacio. Barcelona: Ariel, 1996.

SILVA, L. M. V. da. Saúde e espaço social. In: PASSOS, R. Determinação social da saúde e reforma sanitária. Rio de Janeiro: CEBES, 2010. p. 180-200.

SMITH, R. L. The ecology of man: an ecosystem approach. New York: Harper and Row, 1972.

TUDGE, J. A teoria de Urie Bronfenbrenner: uma teoria contextualista? In: MOREIRA, L.; CARVALHO, A. Família e educação: olhares da psicologia. São Paulo: Paulinas, 2008. p. 211-231.

\section{Contribuição dos autores}

Damelines foi responsável pela concepção do problema, do artigo, e pela revisão bibliográfica. Fernandes e Damiano orientaram e revisaram o trabalho. Ribeiro foi responsável pela concepção do problema e da revisão do artigo.

Recebido: 03/08/2015

Aprovado: 22/09/2015 